Research Article

Isto Huvila*

\title{
Ambiguity, standards and contextual distance: archaeological heritage administrators and their information work
}

https://doi.org/10.1515/opis-2020-0121

received March 18, 2021; accepted August 3, 2021.

\begin{abstract}
Archaeological heritage administrators hold a key position as managers of archaeological information production. This article reports findings of an interview study conducted in Sweden $(\mathrm{N}=10)$ that focuses on providing an in-depth description of archaeology heritage administrators' work with a focus on their information work practices and factors that influence how it unfolds. The findings show that its critical success factors focus on the adequacy and availability of resources, personal experience and functioning collaborations with key stakeholders and colleagues, and balancing between following and interpreting formal guidelines, boundaries and standards of the work. Based on a reading of the findings inspired by Luhmann and White, it is suggested that the administrators' ability to balance between standards and ambiguity and regulate their personal contextual distance to the projects they were working on helped them switch between acting as subject experts and relying on others to maintain a control over their information work-as-whole.
\end{abstract}

Keywords: archaeology; heritage administration; information work; systems theory; professional work.

\section{Introduction}

A shift towards contract-based organisation in development-led archaeology during the past two-three decades around the world has changed the traditional hierarchies, roles and responsibilities of how archaeology is managed and conducted. From the advent of the comprehensive regulation of the archaeology in the post-war years, the prevalent model in many countries was that a limited number of archaeologists and organisations were assigned a responsibility to manage and administer archaeological heritage, conduct fieldwork, make decisions and maintain the accountability archaeology as a whole (Demoule, 2012; Everill, 2012). However, instead of having been a global change from one centralised model to a new network-based one, the development and implementation of contract-based archaeology differs considerably from one country to another. In countries like Norway and Hungary all development-led archaeology is conducted by public authorities (Stjernberg, 2010), whereas elsewhere the models range from largely centralised (e.g. France, Demoule, 2002) to regulated market (e.g. Sweden, Börjesson et al., 2015, and Finland, Haggrén, 2014; Luoto, 2015) and market-based (e.g. Canada, UK, Ireland, Stjernberg, 2010; Dent, 2017) systems. The decentralisation of has typically followed a model of separating administration and oversight from the practical execution of archaeological investigations according to the principles of the broader societal shift from government to governance (Stoker, 1998; Klijn \& Koppenjan, 2012).

The reorganisation of archaeological heritage management has obvious implications to the management of archaeological information and the information work of those who manage it. There are earlier studies on the contemporary information work in the contract archaeology sector, including the quality of documentation (e.g. Andersson et al., 2010), field archaeologists (e.g. Börjesson, 2016), information managers (e.g. Huvila, 2016b), and certain other stakeholder groups (e.g. Huvila, 2017). In contrast, there little systematic research on archaeological

*Corresponding author: Isto Huvila, Uppsala University, Sweden, E-mail: isto.huvila@abm.uu.se 
heritage administrators who are responsible for the administering, overseeing and making decisions - effectively in a key position to decide and regulate how the contract archaeological system works in practice.

The aim of this article is to provide new knowledge on archaeological heritage administrators' (AHAs') work and information work by providing a detailed description of its key aspects and concerns, and theoretically anchored rendition of its constituents. The study is based on interviews with Swedish AHAs ( $=10)$ conducted in 2018-2019 focusing on their views on their information work and its critical success factors, information seeking and use and the digitalisation of archaeological information, the organisation, audiences and stakeholders of contract archaeology in Sweden, and archaeological documentation and its quality. The findings (i.e. why administrators' work and information work unfolds as it does) and what is crucial for its sustainability and success are interpreted using a cross-reading of White (2008) and Luhmann (2005) as a theoretical lens. The systemic work-as-whole perspective is employed to understand the organisation and organising of how information comes to being, is managed and used in archaeology from the perspective of AHAs.

\section{Literature review}

\subsection{Information work in archaeological heritage administration}

There is relatively little earlier research that would have been focussed directly on the information work or practices of AHAs in comparison to, for example, museum curators and collection managers (e.g. Friberg \& Huvila, 2019; Buchanan, 2016; Urban, 2014; Huvila, 2013a) and field archaeologists (e.g. Huvila, 2019a; Olsson, 2016; Khazraee, 2013). Heritage studies literature has inquired into the role and impact of different approaches to archaeological heritage management and the consequences of managing cultural heritage (e.g. Cooper et al., 1995; Dent, 2012; La Salle \& Hutchings, 2012; Smith, 2004; Enqvist, 2014). The focus of these studies has been, however, on heritage or archaeology rather than administrators' (information) work.

Even if their work has not been studied extensively so far, AHAs play a key role in managing and overseeing the contract archaeological process and information production (Huvila, 2011; Börjesson, 2016). Their interpretations of cultural environment legislation and policies steer contractors' writing of investigation reports, a form of grey literature that is the primary informational output of contract archaeology work (Börjesson, 2016; Börjesson, 2015). Huvila (2006) describes their information work as primarily reactive rather than proactive i.e. that their work is focussed on addressing incoming planning and development related requests for comments, making decisions and managing administrative processes. Often to a lesser extent, administrators are sometimes engaged in policy development, land use planning, policy development and development of guidelines. Administrators are frequently over-worked and suffer from a simultaneous overflow of general information and lack of relevant, project and case-specific information. The lack of comprehensive regional surveys of archaeological sites and information systems that would provide access to all existing information in one place can also be a problem. Further, administrators find it problematic that they are responsible for managing projects relating to sites and topics beyond their personal archaeological expertise. Administrators rely on a variety of information sources in their work, the most significant ones being investigation reports, and locally and nationally developed and maintained databases of sites and monuments. The major barriers to information are time constraints and access to information (Huvila, 2016b, 2006), standardisation, relative lack of general coordination of how archaeological information is managed on a country-level (Huvila, 2016b).

In addition to the studies of administrators, earlier literature has investigated and discussed the implications of contract-based organisation of archaeological work, its outcomes (Demoule, 2012; Everill, 2012; Stefánsdóttir, 2019) and implications (e.g. special issue Watson, 2021; Söderström, 2018). Apart from the critical remarks on the impact of marketisation of archaeology on the working conditions of field archaeologists (e.g. Zorzin, 2010; De Clercq et al., 2012; Thomas, 2006; Berggren \& Hodder, 2003), several authors have raised concerns about its impact on the quality of fieldwork and archaeological documentation (e.g. Andersson et al., 2010; Green \& Doershuk, 1998), preservation of investigation data (Huvila, 2016a) and the influence land developers have on archaeological work (e.g. Andersson et al., 2010; Zorzin, 2010; Demoule, 2012; Rocabado, 2015). In contrast, other studies report positive developments, for instance, improved quality and timeliness of reporting (Green \& Doershuk, 1998; Huvila, 2016b). In a broad sense, 
a fundamental challenge of information production in contract archaeology is the same as in all extra-academic knowledge production. It is guided by a mixture of academic, societal and private-sector focused standards of quality and purpose. In such a context, it can be difficult to accommodate for all parallel, partly conflicting expectations and norms without risk of bias and compromised quality (Börjesson \& Huvila, 2019; Huvila \& Börjesson, 2019).

\subsection{Professional knowledge and information work}

In addition to dedicated studies of AHAs' information work, there is a considerable corpus of research on knowledge and information practices across different professional fields. Even if archaeological heritage administration has its peculiarities, it has many similarities with other types of administrative and expert work. Workplace forms a distinct context of information work, behaviour and practices (Byström et al., 2018), similarly to how professions and occupations frame how knowledge and information work is practised in a workplace.

From a profession perspective, archaeological heritage administration is currently best described as an expert occupation than a profession (Sciulli, 2005) even if the earlier research contains indications of development that remind of an on-going professionalisation process. Professionals' and experts' ability to work effectively is based on their knowledgeability of their fields of speciality. Expertise, applying expert knowledge and knowing are, however, complex matters (Winch, $2010 \mathrm{cf}$. Hardin, 2009) to an extent that experts can have difficulties explaining how they know what they know (Bouwman et al., 1987). Having expertise in a particular area requires propositional knowledge (know that), knowing inferential relations between propositions (existing knowledge) and procedures of assessing, testing and obtaining new knowledge (Winch, 2010). Moreover, using Bernstein's (2000) vocabulary, expertise calls for a capability to combine disciplinary insights to fields of practice through operating (in) a region that brings practical situations and theoretical propositions together.

The regionality of how, where and when disciplinary expertise is applicable in practice resonates with the recent emphases of the overlap of knowledge and practice in professional knowledge research (Young \& Muller, 2014) and of the practised and performative nature of information (e.g. Bonner \& Lloyd, 2011; Khazraee \& Gasson, 2015; Huvila, 2018) in information science research. Knowledge (Haraway, 1988), actions (Suchman, 1987), information, and information interactions (Brown \& Duguid, 2000; Miwa, 2003; Cool, 2001; Ekbia, 2009) are highly situated even in such seemingly stable contexts as professional routine work (Kaplan, 1995). Unsurprisingly, information work unfolds as an ambiguous and heterogeneous undertaking, which tends to be difficult to standardise (Huvila, 2018).

Attempts to manage and facilitate expert work by developing guidelines, plans and procedures are often debunked by the very nature of expert work that is geared towards dealing with unexpected and unfamiliar cases (Sharrock \& Button, 2011). Another common problem with increased standardisation is the discrepancy between how it is often conceived as a comprehensive top-down exercise versus how it unravels as a co-constructed and incomplete undertaking with major unintended consequences (Ellingsen et al., 2007; Timmermans \& Berg, 1997) and as a process of accommodation rather than authority and resistance (cf. Huvila, 2018). Studies of various branches of expert work show that apart from hard standardisation, specialists of different fields rely on a large variety of different softer mechanisms and devices of coordination, control and articulation from boundary objects (Star, 1988) to knowledge brokers (Ward et al., 2009). Such mechanisms participate in instituting and maintaining their own regimes (Gießmann \& Taha, 2017) but they do it generally bottom-up rather than as ascribed from the top.

While a part of the underlying rationale in both professional work in general and its standardisation is to improve its efficiency and quality of work, a narrow focus on standards and conformity can lead to a decreasing emphasis of developing new skills and procedures and reflection in practice (Gerdes, 2008). For some, it can unfold as a resource whereas, for others, it can lead to a reducing sense of control of one's own work (Stone-Johnson, 2014), especially if maintaining an overview (Polesie, 2013) of the work as a whole becomes impossible. Apart from major, easily discernible changes, even small adjustments in expectations can lead to consequential disruptions in the efficiencies of this 'workas-whole'. As Star (1999) remarks, they can be difficult to notice and articulate by an external observer - but as we will see later in the present article - also by the workers themselves. Therefore, as she suggests, it is important to describe and understand the developments in both production and articulation work, and to take even any small anomalies and disruptions seriously (Star, 1999). The both are needed to find a balance between the local and the standardised 
(Ellingsen, 2004; Rhee et al., 2015), and to identify who needs to articulate what and when, and what is routine for whom (Wears, 2015).

\subsection{Theoretical considerations}

A possible approach to explore and explain AHAs work with information together with its ambiguities and standards is to turn to its boundaries and systemic characteristics. As the earlier literature suggests, information work as a sub-work (Huvila, 2009) in relation to what can be denoted as the AHAs' work-as-whole depends on maintaining boundaries and regulating boundary crossings independent of the specific mechanisms (e.g. boundary objects or articulation work) of how it is done and how that doing is conceptualised. By drawing on a somewhat eclectic cross-reading of White (2008) and Luhmann (2005), the work-as-whole can be explained as an autopoietic (i.e. self-creating and self-preserving, Luhmann, 2005 cf. Maturana \& Varela, 1980) system that delineates itself from the outer world and selects only certain information from the environment to make it digestible and manageable. A lieu of Luhmann (2005), the formation of a systemic work-as-whole is formed by communication, or in broader terms, by information work that in parallel can be viewed as a functional subsystem of the first. The work-as-whole yields a control regime (White, 2008), and in its own right a parallel regime of work in a quasi-similar fashion to how regimes of work exist next to regimes of control in the writing of Kallinikos and colleagues (e.g. Kallinikos, 2006; Kallinikos \& Hasselbladh, 2009). What is suggested, is that by identifying such features and their related control regimes that enable closures and openings in AHAs' workas-whole, it is possible to bring clarity to the underpinnings, contexts, organisation and organising of how information comes to being, is managed and used in archaeological heritage administration.

\section{Methods and material}

Swedish AHAs were interviewed $(\mathrm{N}=10)$ following the semi-structured thematic interview approach of Hirsjärvi and Hurme (2008). All interviews (average length $60 \mathrm{~min}$ ) were conducted by the author, taped, and transcribed by a professional transcriber. The interviews focused on the interviewees' views on the current state and future prospects of their work and the documentation and management of archaeological heritage and information in Sweden. The interviews covered following themes

1. Interviewees' work - including work duties, priorities, challenges and positive aspects

2. Development-led archaeology in Sweden as an organisational context of interviewees' work

3. Audiences and stakeholders as the human context of the interviewees' work

4. Archaeological documentation - including its quality, evaluation, preservation, reuse and standardisation - as the predominant information product managed and generated in the course of archaeological heritage administration

5. Information seeking and sharing i.e. informational input and exchange in the interviewees' information work

The selection of interviewees was based on purposive sampling of all AHAs employed in Swedish Country Administrative Boards (CAB). Invitations were issued on a rolling basis by using the contact information available in public sources and controlling for a reasonable balance between the different parts of the country, genders and varying lengths of professional experience represented. Even if the interviewees represent a convenience sample, the collected data was considered to be rich and internally complementary enough to be appropriate for the non-confirmatory purposes of the present study. For reporting purposes, the interviewees were assigned pseudonyms (Nils, Mårten, Gorgo, Bataki, Smirre, Dunfin, Akka, Kajsa, Gustav and Rosenbom).

The author analysed the interview data based on close reading (DuBois, 2003) of the transcripts using an approach inspired by the constant comparative method (Glaser \& Strauss, 1967). A preliminary coding of the material was conducted in RQDA 0.3-1 (R 3.6.1). The analysis followed an iterative process of categorising, writing, and recategorising the material. The views, priorities and underpinning factors stem from interview transcripts and are those of interviewees even if the thematic structure of the interviews and their focus on information work, audiences, stakeholders and quality rather than some other aspects of their daily work means that future studies are likely to reveal 
additional details of AHAs' work that warrant both practical and scholarly attention. To control for an over-expression of individual opinions, the analysis placed special emphasis on views expressed by multiple interviewees. Similarly, emphasis was placed on controlling apparent bias relating to the age and professional experience of the interviewees. The results were revisited after one month of the initial analysis using negative case analysis (Lincoln \& Guba, 1985) with the specific purpose of finding contradictory evidence that would decrease the reliability of the conclusions.

All of the interviewees were educated as archaeologists and, except for one, had received their degrees at Swedish universities. One interviewee had an additional degree in public administration. He noted himself that it had an impact on his perspective on his work. Minor subjects studied by the interviewees include cultural environment management (Nils, Gorgo), cultural anthropology (Rosenbom), history (Gorgo, Bataki), historical geography (Gorgo), ancient history and classical archaeology (Bataki), maritime cultural environment (Smirre), ethnology (Smirre) and pedagogy (Smirre). One interviewee had enrolled as a doctoral student, one had completed a licentiate and one a doctoral degree in archaeology.

All of the interviewees had earlier working experience in development-led archaeology before they started working in archaeological heritage administration. Several had experience of working in multiple CABs and two in related duties outside of Sweden. The most experienced interviewees had worked in archaeology and archaeological heritage administration since the late 1980s whereas the youngest had started their career in the beginning of 2010s.

\subsection{Archaeological heritage administrators and their information work}

Nearly all archaeological fieldwork in Sweden falls within development-led rescue archaeology conducted ahead of future land use. According to the current framework of development-led archaeology, the work is contracted to private and public field archaeology operators. A typical contract archaeology process involves both private and public actors. The most prominent stakeholders in the process are the developer (in most cases state agencies, construction companies and landowners), local CAB and the contractor. The national regulatory authority, the Swedish National Heritage Board (SNHB), coordinates and oversees the management of the historical environment, including archaeological fieldwork (RAÄ, 2015; Lönn, 2006; Löwenborg et al., 2021).

The general requirement in Sweden before land use is that developers file an Environmental Impact Assessment (Swe. miljökonsekvensbedömning) of the planned intervention (Schibbye et al., 2007). This assessment includes an analysis of the impact of the intervention on eventual archaeological sites in the area. Commonly, the assessment is preceded by a pre-study (Swe. arkeologisk utredning), which is generally contracted to an external archaeology consultant. If the pre-study concludes that one or several archaeological sites need to be either fully or partially removed, the CAB puts an investigation project (Swe. arkeologisk undersökning) out to tender. To participate in the tender, contractors are expected to submit an investigation plan and budget for the project, including a specification of the type and schedule for reporting.

The tenders are processed and discussed with the developer before a final decision is made by the CAB. After a decision, the chosen contractor conducts an archaeological investigation on the site. When the investigation is completed, the contractor is expected to file a report with the $\mathrm{CAB}$ with specific information indicated in the contract documents. At the end of the process, the AHA reviews the report before formally closing the case. In addition to filing a report with the $\mathrm{CAB}$, the contractors are expected to process all physical finds retrieved during the investigation according to approved procedures specified in the national guidelines and file information in the national sites and monuments registry run by the SNHB (RAÄ, 2015), and for submitting data and providing additional copies of investigation reports to relevant actors and repositories. A major shortcomings with the current procedure is that especially with data that is not directly processed by the receiving institution, there is no systematic follow-up. In addition, regarding the documentation data, its contents and form have not been specified in detail (Löwenborg et al., 2021).

\subsection{Analysis}

The interviews analysed in the present article focused on the interviewees' views on the current state and future prospects of their work and the documentation and management of archaeological heritage and information in Sweden 
with a specific focus on the work, its organisational and human context, and information processing. In the following, the analysis starts with a general narrative of the work of AHAs and the development-led archaeological system as its organisational context proceeded with an overview of its human context of audiences and stakeholders. The analysis continues with a scrutiny of archaeological documentation as the information AHAs are managing and both directly and indirectly producing as a part of their work. Finally, the analysis proceeds to provide a review of AHAs' own information acquisition and sharing that underpin their work with archaeological documentation, and to outline a set of critical success factors of AHAs information work identified in the course of the analysis.

\subsection{Working as an archaeological heritage administrator}

In general, the interviewees described the aim of the work of AHAs in terms of enforcing heritage legislation (Bataki, Dunfin), ensuring the preservation of archaeological heritage sites (Nils, Gorgo) and minimising the damage inflicted on them (Nils, Gorgo). Even if much of the archaeological heritage administrative work revolves around documentation and information management, the interviewees' descriptions unfold the work as a whole as better characterised as a business of minimising damage rather producing information or data. As an illustrative example, Nils described himself as a barrister of archaeological sites. From their own perspective, if AHAs would not do their work, many more archaeological sites would be destroyed without no-one knowing that they had existed (Gorgo, Dunfin, Akka, Rosenbom), the management of archaeological heritage would be less systematic (Nils) or would collapse entirely (Gustav). Also, the information (Smirre, Nils) or knowledge (Gorgo, Akka) resulting from eventual archaeological investigations would never be created.

Multiple interviewees noted that different CABs can have slightly different approaches to their work (Smirre, Kajsa, Gustav, Rosenbom). Contractors with operations around the country sometimes wonder "why you do [it] like this here while others don't do it [in the same way]" (Smirre). In some regions and certain types of contexts (Rosenbom, Smirre) administrators focus a lot on steering development away from archaeological sites, whereas, in Smirre's opinion, some CABs might be more liberal in granting permits to remove archaeological remains from development sites. Mårten remarked that removing an archaeological site is a sign of a failure to preserve it. Similarly to Smirre, he advocated for decisions that would allow development without excavations. The reverse Rosenbom admitted is that major development projects and resulting excavations tend to come with a lot of interesting new archaeological findings.

Work-task-wise, the majority of the interviewees were involved in processing, commenting and management of proposals circulated for consideration on future land-use and development (Swe. remiss) from other departments within the CABs. In addition, administrators consult, manage and make decisions related to the management of developmentled archaeology projects, and planned and submitted permit applications based on the Cultural Environment Act (Mårten, Gorgo, Bataki, Smirre, Dunfin, Rosenbom). Especially in smaller CABs with sometimes only one AHA, the duties varied more and ranged from commenting proposals, making decisions on fieldwork contracts and following up the work and its results to processing heritage and preservation grant applications (Nils, Kajsa, Gustav). Nils and Smirre noted that they have occasionally the possibility to initiate surveys for research or planning purposes and not only focus on administration and management of on-going development-led work.

The specific job duties varied case by case. Especially in smaller CABs administrators experienced that they were making their administrative decisions independently (Nils, Mårten, Gorgo) but as a whole, AHAs work unfolded as highly collaborative. Working together applied both to archaeological heritage administration and work across administrative sectors (Mårten, Bataki). Independence, opportunities to decide and make a difference, and to be able to work collaboratively were all found both rewarding (e.g. Nils, Mårten, Gorgo, Bataki, Akka) and burdensome (e.g. Nils, Smirre, Rosenbom).

Mårten confirmed the calculations done when recruiting study participants that the total number of AHAs working in Sweden is around fifty. In the smallest CABs, a single administrator is responsible for everything whereas the largest ones can have as much as 20 administrators (Nils, Mårten, Rosenbom). Sometimes, the work is divided geographically so that each administrator has a certain number of municipalities to focus on (e.g. Mårten, Dunfin, Gustav). Sometimes, the work is divided at staff meetings based on individual workload (Bataki). Sometimes, certain types of cases are managed by particular administrators with specific education or work experience (e.g. water-related heritage or forests). The geography and history of individual counties influence the types of consultations that are common i.e. 
whether they relate, for instance, to forests and forestry, water or mining heritage (Nils, Dunfin, Gustav). In many CABs, administrators are participating in the work of topic-specific inter-departmental working groups focusing on, for instance, roads or water-related work (Akka, Kajsa) and can have additional duties relating to specific projects and functions (Bataki). Some administrators are also splitting their time between working with heritage management and other duties either permanently or depending on temporary staffing needs (Smirre, Gustav).

The work as an administrator was described by the most of the interviewees as multi-faceted and intellectually stimulating (incl. Nils, Mårten, Smirre, Dunfin, Akka, Gustav, Rosenbom). As Mårten told, "you know almost never what is going to happen at work. Your phone may ring all day, or the police can call you that they have found a skeleton somewhere. It is really exciting”. For Rosenbom, the most stimulating aspect of his work was to follow archaeological investigations and to see when something new was coming up - "there is a lot of archaeology that does not lead to that big results really" (Rosenbom). In smaller CABs, the advantage of working with all types of duties is the possibility to have an overview of everything archaeology-related happening in the area (Nils). However, when the number of AHAs is small, the workload can be high and there is little time for anything else than trying to keep up with managing incoming consultations as well as possible (Mårten, Dunfin, Akka, Kajsa). This gives little room for specialising or focusing on particular types of cases or matters (Mårten, Gustav). The interviewees were also concerned about the longterm sustainability of their work. Juggling with a large number of parallel cases (Gustav) and high workload exhaust people (e.g. Mårten, Akka, Kajsa, Gustav) and make them change jobs (Dunfin). When this happens in an organisation with a handful of employees, or in the worst case only one or two, the potential loss of expertise can be impossible to compensate (Nils, Mårten, Dunfin).

From a process perspective, the most of the interviewees described their work as line work steered by incoming matters (e.g. Nils, Smirre, Dunfin, Akka), or as a combination of line and project-based work (Bataki). As Mårten and Dunfin explained, new cases start often with an incoming phone call from someone asking a question, and (Rosenbom), or with a contact from a colleague working elsewhere in the CAB (Nils, Gorgo). The possibility to work in projects was generally considered as positive (e.g. Kajsa, Mårten, Smirre), especially by those who lacked the opportunity in their daily work (Mårten, Smirre).

The views of whether administrators' work could be described as routine work were split (e.g. not routine for Smirre, routine for Nils, Gorgo). The length of work experience, staff size and workload seem to explain a part of the variation. More experienced interviewees, those working alone or with fewer colleagues, and with a lot of incoming consultations seemed to be more inclined to consider that they were engaged in routine work. As Nils remarked, a lower number of consultations gives possibilities to focus more on individual projects.

\subsection{Development-led archaeology in Sweden}

\subsubsection{Contract archaeological system}

The views about the Swedish approach to organising development-led archaeology as a (semi-)regulated market divided opinions. Even if the opinions were somewhat mixed, the general impression from the interviews is that the interviewees saw a lot of continuity between the past and the present organisation of archaeological work. Some of the interviewees (e.g. Nils, Mårten), especially older ones, considered that tenders and allocation of projects on economic premises harmed scholarly and scientific quality (Nils). Mårten questioned explicitly the possibility to procure knowledge and scholarship as a whole. Nils added that earlier when public institutions (museums) were responsible for development-led archaeology and had a comprehensive responsibility and understanding of the whole region, they were freer to develop pedagogical initiatives and do additional work if deemed necessary (Nils). Rosenbom felt that the procurement processes were arduous and were content that they were not necessary with small undertakings (Rosenbom). The necessity of a procurement-based model was questioned also by referring to Norway where the public institutions are still responsible for both management and fieldwork (Mårten). Also, the complexity of regulations and the simultaneous lack of sanctions (Rosenbom) and the extensive focus on price rather than quality was mentioned as problems (Gustav).

Others had opposite views. Akka considered that "in general we have a much higher quality in archaeology today. When I started [..] it was almost the rule that, for example, it took an extremely long time before reports were delivered" 
(Akka). Gustav compared the Swedish system favourable to other market and non-market-based approaches, and unlike Mårten, considered that the Swedish approach, unlike the Norwegian, improves quality and renewal. Others had similar views of the improved timeliness (Gorgo) and quality or both (Kajsa) in reporting, even if it was admitted that the pressure on field archaeologists had increased (Kajsa). In the past, field archaeologists tended to have more freedom to decide on their work and its goals. The introduction of the contract-based system, procurement processes and the separation of decision-making and oversight from operational work had bolstered the role of CABs as decision-makers and of decision-making in general (Gorgo, Kajsa). Even if experienced contractors are still used as consults when there are no tender-related limitations to do so, the shift to a contract-based system has emphasised the role, independence and responsibility of CABs in the process.

The division of labour between the CABs and contractors was also felt to have clarified the responsibilities (Gorgo, Kajsa) and made field archaeologists more independent in their relation to developers. Now they had a possibility to refer to the $\mathrm{CAB}$ when negotiating the practical aspects of fieldwork and its extent (Mårten). In spite of his reservations to the contract-based approach in general, Mårten welcomed new actors, credited them for introducing new ideas and approaches and noted a positive change in the local archaeology. A downside of the increasing independence of CABs as decision-makers was that the administrators could have difficulties to find knowledgeable colleagues who were not involved in tenders and they could consult (Gustav).

In spite of the critique, the general impression of the interviews is that the contract-based organisation of development-led archaeology was considered to work fairly well (e.g. Gorgo, Akka, Kajsa, Gustav). According to Gorgo, it worked much better at the time of the interviews than when it was introduced. Even if some actors' lack of familiarity with how the system works caused occasional headache (e.g. Smirre, Dunfin), and if some of the interviewees had reservations of its relative advantages and disadvantages, they tended to accepted the shift to a semi-regulated market as a fait accompli.

\subsubsection{National responsibility of archaeology and archaeological heritage}

A closely related question to the organisation of development-led archaeology is who has the general responsibility of the system, of Swedish archaeology and its quality. According to the current legislation, the responsibility lies with the CABs whereas the SNHB supervises the cultural environment-related work on a national level and has a guiding (Swe. vägledande) and coordinating (Swe. samordnande) role in development-led archaeology (RAÄ, 2015; Löwenborg et al., 2021). The interviewees saw not much controversy in how the formal responsibility was distributed but it was possible to sense a tension regarding the practical division of the authority to define appropriate procedures and quality, and to decide if they were met (e.g. Nils, Mårten, Gorgo, Dunfin, Akka, Rosenbom cf. Nils, Bataki, Smirre, Dunfin). Bataki and Dunfin considered that the ultimate responsibility lies with the SNHB as a part of their guiding and supervisory role and that the CABs' role was to see that the legislation and guidelines were followed (cf. Löwenborg et al., 2021). In contrast, Gorgo perceived the line of responsibility in reverse order (as e.g. Löwenborg et al., 2021), whereas Smirre considered that the CABs are responsible in their region whereas the overall responsibility lies with the SNHB.

Nils argued that earlier the SNHB held unquestionably the overall responsibility but that they had explicitly backed from their earlier role. According to him, the responsibility was now more explicitly with the CABs (Nils). Also, Gustav shared the concern that its role and the organisation itself had become weaker in the context of archaeological heritage administration. A part of the interviewees traced this change to the organisational change (Löwenborg et al., 2021) that divested SNHB of its earlier double-role of administering and conducting fieldwork (Nils, Gorgo, Smirre). According to Nils, Mårten and Dunfin, SNHB has also backed from their earlier expert role. As a consequence, the workload and practical responsibilities of the CABs had increased. This was seen as especially problematic in the smaller CABs. Mårten, Bataki and Gustav would have welcomed the opportunity to consult the SNHB for advice as they had been able to do before, and that SNHB would still actively follow CABs' decisions and when necessary, provide feedback on them (Mårten). Instead, they suggested that SNHB had assumed a role to follow-up, describe and report on how CABs were doing their work. "They send out a large number of surveys but answer no questions" (Nils) and submit results from these studies at such a pace that CABs have not enough time to react (Kajsa). In this respect, Kajsa suggested that the CABs should improve the coordination of their efforts, be better at explaining what is changing, and engage in a proper dialogue with the SNHB instead of communicating with each other through surveys and reports. 
Regarding the SNHB, the interviewees were in general in favour of additional and clearer formal guidelines for development-led archaeology (e.g. Nils, Rosenbom, Bataki, Smirre). Certain aspects of archaeological work were considered to be strictly regulated whereas, in others, the interviewees considered that more guidance would be needed (Gorgo). Rosenbom would have welcomed guidelines for the procurement process of archaeological investigations, and Nils for terminology, and for example, for defining the extents of the restricted area around ancient remains. In all of them county-specific variation was considered to be significant. Several interviewees suggested also that the SNHB could provide more guidance by organising cooperation, training, meetings and workshops on, for instance, methods and various aspects of archaeological heritage administration (e.g. Mårten, Akka).

\subsection{Audiences and stakeholders}

Archaeological heritage administration involves multiple stakeholders. Their influence on the work of AHAs varies and as audiences they need to be addressed differently (Dunfin, Rosenbom). The views on the principal stakeholder group varied slightly between the interviewed AHAs. The most of the interviewees considered the local citizens, the public or society in general as the principal audience of their work (Nils, Gorgo, Kajsa, Gustav, Rosenbom cf. Akka). Mårten admitted that the lack of time to engage in communicating the work or its outcomes meant that its overriding focus was in preservation. As a consequence, its principal audience is the future generations rather than any contemporary group of people. Nils's view that the cultural environment itself forms an audience and beneficiary of his work aligns with the same preservation and 'unknown future' oriented mindset.

In a more specific everyday sense, the interviewees considered developers - often municipalities and private companies (Nils, Gorgo, Smirre, Dunfin, Akka, Rosenbom) as key stakeholders of their work. In contrast, even if archaeological fieldwork and documentation unfolded in the interviewees' accounts as research and as a part of archaeological scholarship, the daily links between archaeological heritage administration and academic research were markedly thin. As a result, both research and researchers, re-use and re-users of data and information beyond heritage administration, public communication and the contract archaeology sector surfaced as an almost comparably unspecific audience as the future generations. This does not mean that they were considered unimportant but rather than the issues of secondary research and data or information reuse were out of the immediate scope of the AHAs daily work.

Some interviewees argued that their work is not always very well understood by others including developers, academic archaeologists working at universities or by the general public (Mårten, Smirre, Rosenbom). However, despite occasional minor conflicts (Mårten) and as Dunfin considered that much more could be done to bring different groups together (Dunfin) and expand the existing collaborative networks (Nils), most of the interviewees were largely content with their relations to the different stakeholders of their work.

\subsubsection{Developers}

As Nils explained, in the planning and coordination of contracted archaeological fieldwork, the most important stakeholders are the archaeology contractor and the developer i.e. organisation that is initiating and in regular cases, paying for the work. The prominence of specific collaborators depends on the type of work conducted. In planning related consultations, the work is usually done together with organisations that are proposing or managing future interventions and have them under their jurisdiction. Typically, such matters involve several stakeholders. For example, as Nils explained, the planning of a future railway lines requires working with local and regional authorities and the national railway infrastructure authority, the Swedish Transportation Agency. In contrast, a detail plan for a new housing area requires collaboration with the local municipality and colleagues working with planning at the $\mathrm{CAB}$ (Gorgo). In direct land development related cases, the work is conducted in collaboration with planning authorities and the private or public organisation or individual that is planning to initiate a development project.

The interviewees noted that it is generally easier to work with larger organisations (Gorgo, Kajsa) and colleagues with prior and long-term experience of archaeological heritage processes (e.g. Bataki, Dunfin, Akka). "[With them] you don't have to reinvent the wheel, so to say" (Bataki). In-house archaeological expertise both in larger private 
companies, public bodies and municipalities was seen as a major facilitator of cooperation (Mårten, Rosenbom). With the major actors also the structures and processes of working together were better established (Rosenbom). As a whole, there significant differences between specific actors (Bataki). The most difficult cases tend to be those when individual private citizens are involved, and especially when they are unable to proceed with their plans as they had conceived. It can be difficult to communicate with private citizens and they are more likely to lack background knowledge of how archaeological heritage administration works than professionals (Rosenbom). Mårten exemplified a good workingrelation by telling about a city planner that always calls him directly to discuss new project ideas before proceeding with the planning. There is, however, significant variation between specific organisations and individuals depending on how familiar they are with the procedures and how much they appreciate the value of archaeological research (Akka). Different interviewees mentioned, for instance, the Swedish Transport Administration as an example of a good (Bataki) but also as a difficult collaborator (Dunfin).

Several interviewees noted that they tried to be proactive in following development work in their region and to contact developers for consultation as early as possible. A part of their work is to explain to developers how the contract archaeological process works (e.g. Smirre, Dunfin). It is not, however, always easy to know and find time to follow what is going on. Sometimes, despite an early contact, the developers do not always take action (Smirre). They can also be displeased of legal requirements, or of the archaeological process as a whole - sometimes for understandable reasons (Dunfin, Akka). As a whole, however, Smirre suggested that a general increase in the acceptance of the importance of archaeological work in society has had a positive impact on the attitudes of developers and planners and improved collaborations with them.

\subsubsection{Contractors}

Another central stakeholder group for administrators are the contractors i.e. archaeology operators that conduct the actual fieldwork on behalf of the CABs. All interviewees underlined that their relations with the contractors are very good even if they are at the same time admittably also somewhat complex and delicate. Contractors are selected based on their expertise. As Bataki underlined, administrators work hard to grant contracts as evenly as possible without favouring any single operator. Especially in the more remote parts of Sweden, the pool of contractors participating in tenders tends to be relatively stable (Nils) and the CABs know the local actors and their ways of working (Rosenbom). Both practical reasons and the relative lack of expertise in local archaeology makes it often difficult for operators to undertake work that is far away from their home-base. When needed and available, especially specialised expertise is still contracted from farther away (Nils, Rosenbom) from contractors with a competence, for instance, in a particular method or topic (e.g. Smirre, Gustav). Also the size of the contractor matters when deciding on who is best qualified especially for larger projects that demand greater capacity of the operator than smaller ones.

The local contractors were considered crucial to the success and continuity of high-quality fieldwork (Nils). Their accumulated expertise of the region was seen as a vital resource for CABs when making administrative decisions and planning interventions. They were perceived more reliable long-term partners than self-employed archaeologists because they tend to be less vulnerable to staff absence (Gorgo). At the same time, however, because the contractors are participating in tenders, there are certain limits on how their expertise can be used in practice. From the perspective of the economic survival of these often small to middle-sized actors, they must regularly win tenders. In comparison to large contractors, their local focus and relative lack the financial resources put them in a difficult position (Gorgo). At the same time, their often strong local market position was seen as problematic from the competition perspective. One of the interviewees expressed critical remarks especially of regional museums and suggested that their income from contracts did not necessarily end up in improving their fieldwork operations but to support other activities at the museum. Another interviewee had a somewhat different perspective. The involvement of local museum could provide added value and long-term impact through extended pedagogical and outreach activities developed in collaboration between locally contract archaeologists and museum professionals. Contractors coming from the other parts of the country were seldom considered capable to allocate their time to allow such extended collaborations.

Even if the interviewees were generally highly content with the quality of the work of the contractors and the collaborations, some admitted that there are differences between different contractors and especially between specific individuals doing the work. This applied both to the results and to how and how independently they worked (Smirre, 
Rosenbom). In parallel, other interviewees considered that the differences were fairly small, especially with smaller projects (Dunfin).

\subsubsection{Colleagues and other collaborators}

In addition to consulting fellow AHAs and colleagues at other departments (e.g. Mårten, Gorgo, Bataki) at the CAB, the interviewees told about multiple formal and informal, sometimes overlapping, networks of colleagues (Nils, Smirre, Gorgo, Dunfin, Akka, Kajsa) and collaborative projects (Gorgo, Rosenbom) organising meetings on a more or less regular basis (Rosenbom). Some of the networks brought together multiple CABs located in a particular area of Sweden (e.g. Nils, Bataki, Dunfin, Akka, Rosenbom). Others were national (e.g. Kajsa) and organised topic-wise to focus on, for instance, water-related heritage (Smirre, Dunfin), forest (Nils) or broadband (Bataki) related questions. Some of the groups were larger and formal whereas others told that they had created also their own small informal advisory groups (Smirre). Cooperation was generally facilitated by the small number of colleagues working in individual counties (Nils) and nationally (Mårten) as administrators, and as archaeologists in general (Mårten).

The interviewees referred to collaboration with colleagues working with other aspects of the cultural environment and other branches of administration to a varying extent. Mårten noted that the cross-sectoral collaborations make his work simultaneously enjoying and challenging. Even if cooperations generally worked well, some of the interviewees noted that as archaeologists they ended up "educating” (Dunfin) their fellow administrators at the CAB on cultural environment legislation much similarly how they needed to educate developers. The interviewees tended to be more content when they were consulted proactively than when they had to correct their colleagues afterwards (e.g. Dunfin cf. Kajsa, Rosenbom). The forms and intensity of collaborations seemed to vary but in general, the interviewees engaged in both formal departmental collaborations or topic related working groups (Nils, Rosenbom) and had informal contacts within their CABs. In some CABs, the colleagues were engaged on a case by case basis rather than as a part of permanent arrangements (Mårten).

In addition to colleagues, the interviewees mentioned a large number of other collaborators they were working with regularly. Local and regional museums and cultural centres are key partners for many administrators (Nils, Mårten, Dunfin) but the spectrum of contacts ranged from environmentalists (Nils) to researchers in different disciplines (Smirre) and various public authorities from the frontier guard and the armed forces to the police (Smirre, Nils). For instance, Gorgo told that he works in a very inter-sectorial manner and consults other archaeologists but also, for instance, biologists and museum professionals. Several interviewees regretted their relative lack of contact with (universitybased) researchers and educators (Gorgo, Bataki, Akka, Kajsa).

\subsubsection{General public}

The perception of the extent their contacts with the general public varied between the interviewees. Mårten, Bataki, Kajsa and Rosenbom told that they have a lot of contact with the public because they were contacted relatively often by private individuals on matters relating to archaeological sites located on their property. Besides administrative contacts with individual citizens, the interviewees had also some contacts with local history and heritage societies (Nils, Gorgo, Bataki).

In contrast, the interviewees were less satisfied with how much archaeology was communicated to the public. As Kajsa underlines, there is much unused potential in communicating and popularising archaeological research for the general public around the world. She argues, however, that currently, no-one has a proper responsibility to do that. Gorgo regretted that personally, he had not enough time to engage in public outreach. In contrast, Smirre, Akka and Kajsa underlined that public relations is not a part of their work as administrators. They can request improvements in popular scientific summaries of archaeological investigation reports but otherwise, their possibilities to engage in public communication are limited (Smirre, Akka, Kajsa).

Many of the interviewees underlined also the importance of communicating archaeology to the general public and politicians as means to improve their understanding of archaeological work (Mårten, Smirre, Dunfin) and to improve and maintain its legitimacy (Smirre) not least for ensuring the preservation of archaeological heritage (Mårten). Mårten 
remarked that sometimes large-scale excavations can turn the local attention to the past and make it a significant part of the local identity but ideally, archaeologists would not be needed to tell how important a particular site is. The individual members of the public would feel a sense of connection themselves (Mårten).

\subsection{Archaeological documentation}

Besides their work and its organisational and human contexts, the interviewees were asked about their views of archaeological documentation they managed and worked with, its quality and evaluation, preservation and re-use, and the impact digitalisation, standardisation and of explicit research questions in field archaeology for the documentation and how it unfolds.

\subsubsection{Quality and quality development}

The interviewees were largely content with the quality of archaeological documentation they received from the contractors. The quality was also considered to be fairly even between different actors (e.g. Mårten, Gorgo, Rosenbom), and even if there are differences in perspectives and between how individual contractors do their work, AHAs saw very few problems (e.g. Mårten, Gorgo, Bataki, Akka, Kajsa, Rosenbom). As Nils stated, "the organisations we collaborate with keep a very high quality [..] we don't think that there are major problems. We get what is required to be handed in, and [we get that] in time, for the time being. You need to be quite happy about that”. Sometimes, the sub-optimal quality does not depend on the contractor but other circumstances (Smirre) like bad weather. Also, Mårten and Kajsa emphasised that they trusted the contractors and that it is beyond his capabilities and not a part of his job to attend to every detail and determine the quality and relevance of individual pieces of documented and preserved information. Despite this, Kajsa was still confident that she knows what is going on. According to Mårten, administrators should not determine or ask "what you [contractors] have measured, why you have measured that and so on. It's not, we don't go to that level and I don't think we should either because the archaeologists are that much ahead of us in the development [of methods and field practice]" (Mårten) What an administrator should do is to make sure that the site is documented by using appropriate methods and that the work is done as scheduled even if the original plans could not be followed in detail (Mårten, Kajsa). Some of the other interviewees (e.g. Bataki, Akka) - as it seems, with less workload - suggested that they steer documentation work in more detail by shepherding report-writing, doing spot tests, and, for instance, by following up certain technical details of documentation data files (e.g. Bataki). Bataki admitted though that he "is a little nerdy when it comes to the material“ (Bataki) and probably does more to control its quality than many others do.

The national system for development-led archaeology has also implications for the quality of archaeological documentation. A key premise of quality is that the existing historical environment legislation and formal organisation of archaeological work make it possible to systematically investigate sites ahead of development (Kajsa). Even if Gustav criticised the Swedish approach for being price rather than quality-driven, Rosenbom underlined that he and his colleagues try to emphasise quality instead of merely looking at the price. Sometimes the explicitness and clarity of documentation are at odds with business concerns. Bataki explained that if a pre-investigation would suggest a need for a full excavation at a particular site, the investigation report needs to be detailed enough to help both the pre-investigator and other contractors to submit a tender for the excavation. However, from the perspective of the contractor that conducted the pre-investigation, the report should not be too detailed to help others to win the tender (Bataki). There are also other issues that make the best possible quality of documentation a compromise. The aims of the investigation are difficult to write in an unambiguous enough manner to encompass what an administrator needs to know about a specific site, what is reasonable to achieve, and financially viable (Nils, Bataki, Akka, Kajsa).

The interviewees gave also examples of measures for developing and improving documentation and its quality. Rosenbom described a plan of action his colleague had developed that enumerated preferable methods for analysing a particular category of remains. After the plan was finalised, it was introduced and discussed at a workshop held with contractors. Besides the explicit measures developed to improve the quality of documentation, the interviewees tended to consider that the contemporary techniques and technologies are better than older ones and contribute to an improved quality of documentation. As Mårten remarked, the quality "is as good as it can be” (Mårten). Several 
interviewees pointed also to the digitalisation and increased standardisation of working methods, processes and information infrastructures as a quality driver (Gorgo, Bataki, Dunfin, Akka, Kajsa, Gustav).

Finally, in addition to methods and techniques, human factors are important for the quality of documentation. Nils, Smirre, Kajsa and Gustav underlined the importance of communication and continuous dialogue with the contractors as a premise of good quality documentation. Bataki underlined further that someone needs to be responsible for assuring the quality of the material.

\subsubsection{Good and bad quality}

If the premises of good quality documentation were deemed complex, the question of what constitutes good quality was equally complicated. Bataki suggested that the understanding of good and good enough varies between institutions and individuals. He would have welcomed clearer guidelines of what is "good quality" and, for instance, "reasonable cost". Sometimes, especially with detailed questions relating to specific types of remains or historical periods, there can be different scholarly opinions on appropriate documentation methods and interpretations. In such cases, it can be difficult for an AHA who is non-specialist in the specific matter to determine whether a proposed approach is good or bad (Akka). General indications of good quality documentation mentioned by the interviewees included timeliness of work (Nils, Mårten, Gorgo, Akka), use of appropriate documentation methods (Mårten, Rosenbom) and file formats (Bataki, Dunfin), and presence of accurate height data (Rosenbom) and appropriate types of illustrations (e.g. crosssections, Akka). Further criteria comprised a structure of documentation that helps to understand the context and relations of observations (Akka) and a level of detail that makes it possibility to recreate a site or feature on the basis of what has been documented (Rosenbom). An elementary indication of good quality is also that a report is complete and completed (Nils, Mårten, Gorgo).

Besides the need to ensure the quality of individual projects and pieces of documentation, Bataki underlined also the importance of maintaining a reasonably uniform level of quality across the country especially from the perspective of future research use of the material. According to Gorgo and Akka, good quality documentation should not either be a mere enumeration of observations but incorporate an interpretation of the findings and function as a basis for creating new knowledge. Nils contrasts the current ideal with earlier objectivistic views and reports from the 1980s that could consist of mere coordinates and numbers. From today's perspective, such reports might not contain "any information at all” (Nils). Besides the variation in documentation ideals (Börjesson, 2016) in different times and the differences between individual contractors and archaeologists noted earlier in this article, Nils and Bataki remarked also that sometimes an inferior quality of a report or documentation data could depend on imprecise or poor investigation guidelines given by AHAs.

As a whole, the interviewees tended to focus on what "material" (Bataki) the contractors provided them rather than to explicate in detail what information or documentation they were expecting. One of the interviewees with earlier experience of working in several other European countries had made a related observation. The interviewee criticised the Swedish practice of being both unspecific and very selective of what types of documentation was considered to be important to keep. He acknowledged the drawbacks of over-documentation and too specific guidelines. They undermine the importance of respecting archaeologists' professional judgement and considering project-specific circumstances. He admitted, however, that he was missing richer documentation from the investigated sites.

\subsubsection{Evaluation}

The interviewees had developed varying approaches to follow up the quality of documentation. A major difficulty is, as Gorgo admitted, that for someone who has not been on the site doing the work, it is impossible to know how meticulous the contractor has been. Apart from focusing on the documentation, the interviewees did also underline the importance of communicating with contractors during the project by visiting the site or by discussing by phone or other means (Nils).

At the minimum, especially when the lack of resources did not permit closer inspection of documentation quality, the interviewees focussed on ensuring that formal requirements of submitting complete sets of documents were met 
(e.g. Mårten). Some AHAs told that they looked at the material in detail whenever possible (e.g. Bataki, Smirre) even if none of the interviewees suggested that they were able to read every single piece of documentation in detail (e.g. Smirre). Perhaps unsurprisingly, two interviewees suggested that it would be welcome to have a two-step submission process with a superior or an editor to read through all the documentation before it is archived and sent further from the CAB (e.g. Bataki, Akka).

The necessity of conducting a closer evaluation of documentation depends on various factors. If the contractors are experienced and have a history of delivering good quality documentation, there is seldom a reason to question their judgment (Nils, Rosenbom). Akka explained that her premise is that all archaeologists are very engaged in what they are doing and if someone is not, it is easy to see in the documentation. Gorgo told that he checks who has done the documentation, what type of information it is, and if he himself finds it credible. He also makes comparisons between different sources. For instance, sites an AHA has personally registered before, historical maps, place name registry, and geology of the site can provide useful points of reference (Gorgo). The lack of explicitly stated grounds for an interpretation or something that deviates from earlier evidence can raise questions of the accuracy and reliability of documentation (Gorgo). Long work experience tends to help to judge the quality of work (Nils, Smirre, Dunfin, Gustav): "You are pretty used to reading reports so that often you can see if the argumentation makes sense and so on, and if they have been careful in taking their notes" (Nils) or as Dunfin emphasised, "it is the experience; end of discussion!". In the end, even if "it sounds terrible" (Smirre), the feeling that something might be wrong is often based on intuition rather than specific details.

\subsubsection{Preservation}

The interviewees had varying opinions about the archiving and preservation of documentation and records. There were no major concerns that the key records, as described by the interviewees, i.e. the contract documents, the administrative permit to interfere with an archaeological site, budget and investigation report would not be archived properly (Nils, Bataki, Kajsa). In contrast, Akka and Gustav were concerned that too little information might be preserved. They were especially concerned about the faith of the primary investigation data. Also Mårten admitted that the disposal of documentation material is a difficult question because it is impossible to say what information can be valuable in the future.

Even if digital archives have been introduced in county administration (e.g. Nils, Bataki), the interviewees pointed to shortcomings in the current systems that are geared towards keeping administrative records and less suitable for managing information. CABs have launched a joint project to complement existing digital archives with functionality to link geographic information to archival records (Bataki) but as Kajsa remarked, a fundamental problem from her perspective is that the digital archives consist of files rather than of data. Mostly the digital data are considered as working material and not archived at all at the CAB. Sometimes, if digital data is included in the archive, it has been exported directly from a field documentation system and contains only a part of the existing information, links and relations that were present in the original documentation system (Akka). A major problem is that none of the currently existing systems provides comprehensive means to deposit primary investigation data in a unified data structure (Akka, Kajsa). Kajsa noted further that even if the preservation of new data would be solved soon, there is a lot of legacy data that would need to be treated separately.

Apart from placing the case records in the local archive, some documents and information are deposited also in other repositories and databases (Nils). These include the new Swedish Historic Environment Record (http://app.raa. se/), a national infrastructure for information on sites and monuments and archaeological fieldwork (Larsson et al., 2017; Löwenborg et al., 2021) launched in stages at the time when the interviews were conducted.

\subsubsection{Research use of documentation}

Considering the fundamental aim of archaeological fieldwork to contribute with new knowledge about the past that was recognised by the interviewees, they regretted that it happens all too seldom (e.g. Gorgo, Akka). A significant number of sites are investigated and documented annually, and selected parts of the documentation are archived but 
seldom, if ever, used to a significant extent for producing new archaeological knowledge. Kajsa added that sometimes municipalities are wondering for a good reason why they are financing archaeological fieldwork and how they benefit of it. Even if the keeping of primary research data was considered to be the best approach to facilitate new research with new research questions and perspectives (e.g. Bataki), Nils remarked that some of the data have a relative "best-before date". A part of the techniques and technologies used in data gathering and even research questions become out-dated fairly quickly (Nils). This underlines the importance of interpreting findings and not only collecting data that Gorgo and Akka emphasised as a fundamental criterion for good quality documentation.

A major barrier to methodical use of documentation material is that currently no-one has explicit responsibility to pursue systematic research based on development-led archaeology data (Kajsa). Development-led archaeology is not necessarily well understood among the archaeologists who are working at universities (Gorgo, Bataki, Akka, Kajsa), and the documentation that stems from contract archaeology is not always easily applicable for secondary research use. It might lack details that are vital for addressing specific research questions that were not anticipated when it was created and the general requirements of how development-led archaeology works might not always coincide with those of optimal research data production (see e.g. Bataki, Nils). Akka recalls that back in the 1990s, it was customary in some parts of Sweden to invite archaeology students to study trips for presenting possible topics for course and thesis work. These trips were successful and generated several studies from bachelor-level course papers to doctoral research. On the positive side, Kajsa had noticed that investigation reports are being used as source material in archaeology courses more than before but as a whole, the documentation material has difficulties to find its way to research use.

\subsubsection{Research questions}

One of the guiding principles of Swedish development-led archaeology and means to improve its scholarly relevance and impact is that all full investigations are expected to be guided by explicit scholarly research questions (RAÄ, 2015). Even smaller pre-investigations should always have an aim stated in the contract documents. Smirre underlined that he and his colleagues are careful that research questions are stated explicitly. However, even if all investigations are about seeking new knowledge, the explicitness of research questions tends to vary between individual projects. In smaller projects, the questions cannot always be especially profound (Mårten, Smirre, Akka) even if it is important to acknowledge that even very simple questions on small investigations can have major implications (Smirre). While many small-scale pre-investigations would not produce new explicit archaeological knowledge, they are needed to ensure that future possibilities of generating knowledge are not compromised (Mårten). In larger investigations aiming at documenting and eventually removing a site, the research questions have a more prominent role. At the same time, however, when sites are removed, a central research question is always to "preserve [the site] for the future [..] in the documentation" in addition to addressing additional, more specific questions (Bataki). In such cases, even if the analysis and interpretation of the site would be made with specific research questions in mind, it would be important to keep the primary investigation data and make it available for future researchers that might come with very different questions in their mind (Bataki).

The aims and research questions are based on what is known about the site and area, results of earlier investigations and other relevant sources available (Mårten, Bataki, Dunfin, Rosenbom). The contract document can provide an outline or guidelines for research questions and themes (e.g. Iron Age settlements, or the function of the site) leaving room for the contractors to develop more detailed questions and describe methods to address them (Akka). Because there are limits to the expertise of an individual administrator, the contractors are often more knowledgeable of specific types of sites (Akka). Rosenbom explained that when he knows the site and has particular questions about it, he can be more specific about the details of the investigation plan. When an investigation is planned on a site he knows only superficially, he usually lets the contractors write a plan and accepts it if it looks reasonable. Dunfin described a case when ahead of an excavation, a contractor disagreed with a set of questions in the tender that were formulated on the basis of the conclusions of a pre-study. Based on her expertise in that particular area, the disagreeing contractor had determined the correct nature of the site and proposed a different, more relevant, set of research questions. 


\subsubsection{Standardisation}

Besides research questions, another popular means to steer archaeological documentation practices is standardisation. Adequacy of standardisation and existing standards are a constant topic of debate. Apart from formal standards and guidelines, archaeology is also full of unquestioned conventions (Akka). Often new conventions arise and standardisation can happen almost coincidentally as a consequence of the introduction of new tools and information systems such as the Historic Environment Record. At the same time, it can be difficult to purposively enforce a standard because of the relative lack of penalties of non-conformity (Smirre, Dunfin, Rosenbom).

Even if many interviewees seemed to agree that the current general level of standardisation is adequate (e.g. Gorgo, Dunfin), they noted many elements that could be better standardised. These suggestions range from report templates and reporting customs (Akka) to terminology and diverse unmotivated county-specific conventions of, for example, measuring the extents of archaeological sites and their related restricted areas where breaking up the soil is prohibited (Nils).

It is difficult to conceive that all archaeological work could be ever standardised. "You have to be allowed to think by yourself when you are working [in archaeology] [..] sometimes you don't get the answers you would expect but you still have to present the results" (Nils, see also Mårten, Rosenbom). "Sometimes the world is [..] complicated and there has to be room for that" (Dunfin). In Sweden, the local conditions and features of the cultural environment differ significantly across the country (Nils). Overdriven standardisation, rigid guidelines and overemphasis of formality of documentation can lead to an unproductive uniformity of investigation methods (Gustav) and reports, classification of sites (Rosenbom) and finds (Bataki) and eventually, to a loss of information (Mårten).

\subsubsection{Digitalisation of information}

A final aspect of documentation that was touched upon in the interviews was digitalisation and its impact on AHAs work. The administrators work to a large degree with digital information even if there is a lot of information that remain undigitised. This applies to the management of administrative documents and records (Nils, Bataki, Akka, Gustav) as well as new archaeological documentation (e.g. Bataki, Smirre, Dunfin). Digitalisation was considered by the interviewees in overwhelmingly positive terms. It was portrayed as an opportunity to improve the efficiency of their own work and the quality and standardisation of archaeological documentation (e.g. Gorgo). Digitisation was not considered as a threat even if some of the interviewees acknowledged the presence of certain unsolved issues, including digital preservation (Mårten) and the risks relating to an overemphasis and blind focus on data-capturing rather than reflexivity and interpretation in the field (Gorgo).

Because older reports, records and investigation documentation are available only in print, and unsurprisingly, several interviewees dreamt of complete digitisation of all earlier archaeological documentation material (e.g. Bataki, Rosenbom) and a complete archaeological information system with map-based search functionality (e.g. Bataki, Akka). The comments on the on-going deployment of the Historic Environment Record generated primarily hopeful remarks even if some of the interviewees pointed out that it solves only a part of the currently identified information and management needs (Nils, Gorgo, Bataki, Smirre, Dunfin, Akka, Gustav, Rosenbom). The same applies to the contractors and their increasing adoption of digital documentation methods (e.g. Bataki, Smirre, Dunfin). Whereas it was seen generally as a positive trend, some interviewees were not convinced that the opportunities were realised yet and called for new fresh ideas (e.g. Rosenbom, Smirre).

\subsection{Information seeking}

In the pursuit of developing a comprehensive understanding of AHAs information work, in the following, the present article turns from the organisational and human context and informational content of their work to how administrators seek and find information they themselves need in their work. As a whole, archaeological heritage administration is information-intensive work. None of the interviewees complained that they would not get enough information to conduct their work properly (cf. Nils, Mårten, Gorgo, Smirre, Akka, Kajsa, Rosenbom) even if the majority of them 
admitted that they have not time to keep up with current research and had many other barriers to cope with. A long working experience was an advantage and gave confidence also in information seeking (Mårten, Rosenbom).

In contrast, the presence of inaccurate and incomplete information (e.g. Nils, Gorgo, Bataki, Rosenbom) and pervasiveness of non-digital sources were considered as major hindrances (Nils, Bataki, Rosenbom). In a part of the country, the lack of complete archaeological surveys was also considered problematic (Nils, Rosenbom). The major consequence of the lack of adequate information is that when archaeological assessments are based on educated guesses, a lot of archaeological heritage and information are destroyed without being properly investigated (Nils).

\subsubsection{Information sources}

The interviewees received most of their daily information through internal channels at their CAB even if they emphasised the parallel importance of their formal and informal networks. Internal administrative and records management systems (Nils, Mårten, Bataki) and geographic information systems, map applications (Rosenbom, Mårten), and national sites and monuments register (Gorgo, Dunfin) are of central importance. Web searching (Bataki, Akka) and personal registers of reports and other documents could be used to complement officially endorsed systems (Mårten). Training sessions and official documents provide information on legislative matters and guidelines (Gorgo). Nils mentioned also social media as an occasionally relevant source of information although he also noted that as a public servant, he has to be careful what he himself publishes and shares.

\subsubsection{Investigation reports}

Reports function as the primary source of information about past investigations and an "answer to the [questions posed in] the contract documents" (Nils). At the same time, they are also the end product of an archaeological investigation, even if to a certain extent it "might be really that a new housing unit is built but [formally, it is] that we get a report, result from this completed archaeological investigation" (Gorgo). Reading reports is helpful also to keep updated about what is known about the local past (Mårten, Bataki, Akka).

However, in practice, much of the information used in decision-making about a site comes directly from the contractors during an on-going investigation well before the final report is completed (Nils). Individual reports differ from each other similarly to the individuals and their level of knowledge that are conducting an investigation and writing them. The use of older reports can be difficult due these differences and the fact that they and their contents become to a certain extent outdated in time (Nils) as archaeological knowledge advances and interpretations and priorities change.

\subsubsection{Colleagues and collaborators}

The interviews showed the prominence of colleagues and collaborators as an information source. A contributing factor is the small number of administrators and archaeologists in general. The consequence is that the most of the people know each other (Mårten). Fellow administrators provide often useful procedural information whereas the contractors were generally admitted to be an invaluable source of information on the practicalities of fieldwork (e.g. Mårten, Gorgo, Akka, Kajsa, Rosenbom). "We try to keep a pace with contractors but [..] you have to be damn humble and say that I can’t follow. I know nothing about this type of analysis” (Mårten).

Much of the exchange took place in email, mailing lists or phone conversations (e.g. Nils, Mårten, Smirre, Kajsa) and meetings (Rosenbom, Mårten) but the interviewees mentioned also seminars and workshops. They are organised both regionally and nationally and provide opportunities to share information, especially on particular actual topics (Rosenbom, Mårten). Internal information channels within CABs are important for information exchange even if Nils complained that the internal (non-technical) networks are not always working as well as they could. In some collaborations, the workflows and forms of exchange followed established procedures but the variety and eventdrivenness of much of the work meant that they could vary a lot (e.g. Rosenbom, Gorgo).

Much of information sharing with colleagues stems from tight collaborations and through strong ties between individuals who are and had been working together for an extended period of time. Mårten sits together with his only 
AHA colleague in the same room "next to each other so that I know almost always what [the colleague] is doing and he knows what I do. We talk really a lot about the matters. I mean, we take each others' phone calls whenever needed". He continued and explained that after having worked for a long time on a specific topic together with another person, "you work in a specific way". They both have a lot of knowledge that cannot be "found [i.e. is not written] on paper" and they have a habit of making jokes that they should not travel in the same car if something would happen. Similar, if not quite as intensive but often equally informal exchange could be sensed also between other interviewees and their colleagues - both within local archaeological heritage administration and between administrators and individuals described as colleagues or in colleague-like-terms working outside their own organisation (e.g. Nils, Gorgo, Bataki, Smirre). Depending on the context of exchange (e.g. formal network or personal contacts), the information sharing could be specific to a topic of shared long-term interest or focused on the immediate needs of the participating individuals (Nils).

The downside of working alone at smaller CABs is the lack of fellow administrators to talk to. Many interviewees agreed explicitly that the presence of at least a colleague or two was crucial. Sometimes collaboration and information exchange is hindered by a silo mentality (Nils) even if many interviewees considered that the cross-sectoral exchange tended to work well (e.g. Mårten). The limits to how and when contractors could be consulted could increase the sense of loneliness (Smirre, Akka, Kajsa). The colleagues were asked for advice and information, used for testing ideas and discussing procedures (e.g. Mårten, Gorgo, Bataki, Rosenbom). Independent of the formal or informal nature of the exchange, the networks and the possibility to be able to discuss with colleagues were highly appreciated (Kajsa).

\subsubsection{Scholarly literature}

The interviewees read published archaeological literature to a varying degree (Nils, Bataki). Keeping up with current research was considered to be difficult (Mårten, Gorgo, Smirre, Dunfin, Akka, Kajsa, Gustav, Rosenbom) and was considered to require time and personal initiative (Gorgo), and even designated time or research leave (Dunfin). Smirre and Gustav regretted the lack of access to scholarly literature at their CABs. Whenever an up-to-date overview volume of local archaeology was available, it was highly appreciated (Rosenbom). Having completed a doctorate or being enrolled as a doctoral student helped Nils and Gustav indirectly to keep updated on recent research. Rosenbom, Dunfin, Kajsa, Gustav and Mårten remarked that they tried to attend scholarly seminars even if there is not always enough time. Rosenbom remarked specifically that a good seminar could provide access to actual information in a condensed and easy to digest form.

\subsubsection{Information encountering}

Finally, some of the interviewees remarked that they benefited sometimes of unplanned information encountering. Gorgo referred to occasional unplanned information encountering but did not consider that it happens especially often. Some interviewees described also their own experience as a source of information. Rosenbom explained that being able to identify a specific site is based to a significant degree on "earlier experience, really" (Rosenbom) and Mårten describing how "I have worked so long both as a field archaeologist and here in this job that I feel myself very secure in my position. But I am not that cocky. It is important to discuss in a group” (Mårten). Mårten described his congenital information seeking further by remarking that sometimes when "you have an idea, you know intuitively" (Mårten).

\subsection{Critical success factors of administrators' information work}

Moving from a thematic analysis to breaking down the material as a whole, it is possible to identify a small number of recurring factors that are repeated from one theme, context and interviewee to another. These elements that explain the dynamics and success of the interviewed administrators as a whole, include the availability of sufficient resources and infrastructures, experience, adequate room for local variation in practices, and functioning collaborations with relevant stakeholders. 


\subsubsection{Resources and infrastructures}

While the interviewees tended to consider that they can get their work done in one way or another, it was apparent that the development of certain currently lacking key resources and infrastructures would make a significant difference for their work. An apparent key problem for many interviewees was the availability and quality of information (e.g. Nils, Rosenbom) - even if, for instance, Rosenbom admitted that the quality of information some information, for example, geographical information from the Swedish Land Survey, had improved. In the northern parts of Sweden, the lack of a comprehensive regional survey of archaeological sites means that archaeological heritage administration relies on highly incomplete information of the local archaeology (e.g. Nils, Mårten, Rosenbom). The difficulty of accessing nondigital legacy data was another key problem (e.g. Bataki, Rosenbom) even if it was only one specific aspect of a much broader issue of the general heterogeneity and dispersion of data in multiple repositories and organisations, and a lack of comprehensive syntheses of data and knowledge (cf. Mårten, Bataki, Kajsa, Rosenbom).

The adequacy of staffing varies substantially between the different CABs (e.g. Nils, Mårten, Akka, Kajsa). A small staff is not necessarily a critical issue for the daily work of AHAs if the volume of development work in the region and, consequently, the number of consultations remains low. The major risk of having a small staff relates to knowledge retention when one of the few or the only AHA leaves the CAB. At the same time, in some CABs, both in those with a smaller and relatively large number of administrators, the employees were struggling under an immense workload. Independent of how they experienced their amount of work, in general, the interviewees would have welcomed more designated time for continuing education and training, and better opportunities to keep updated on the latest developments in archaeological research and methods (e.g. Mårten, Smirre, Dunfin, Akka, Gustav).

\subsubsection{Experience}

The impact of work experience as a critical driver of being successful in working as an AHA could be read throughout the interview transcripts. Less experienced interviewees remarked how they occasionally struggled with their lack of knowledge of the region where they were working while more experienced ones described how they could work to a large extent on the basis of their first hand experience and knowledge of the local archaeology. Experience was also important for acquiring specialist knowledge of particular types of archaeological sites and investigation methods.

Besides experience of archaeological heritage administrative work, background in field archaeology was considered as especially useful for anyone working as an AHA (e.g. Mårten, Rosenbom). It helps to understand the contractors' situation in the field but also to form an opinion of archaeological sites already in the office before engaging in any actual fieldwork (Rosenbom). Mårten commented that it might be useful for administrators to be able to work in the field once in a while to maintain their fieldwork competence. Dunfin noted that in addition to fieldwork experience, general experience of work, life and archaeological research (implied, beyond fieldwork) is also important for the success of her work (Dunfin).

\subsubsection{Boundaries and flexibility of work}

Another theme that appears throughout the interview record relates to defining the boundaries of work and how it is conducted. Some of the interviewees expressed concerns regarding the lack of standardisation of archaeological work and documentation. For instance, Kajsa argued that the CABs need to start working better in accord to avoid unmotivated differences between the counties. This applies especially to such cases as forestry works that seldom lead to excavations but where the regional policies have been varying a lot. To a degree, some of the interviewees were inclined to think that the CABs are already working similarly to each other (Kajsa) and the main problem is that the investigations and their results are seldom synthesised in a larger context across regions (Kajsa). As a whole, the heterogeneity and contextuality of archaeological work were seen mostly as a matter of fact rather than a problem. "A lot is left to the discretion of CABs, and because every one of them is an independent public body [Swe. myndighet] it means that there are unavoidable differences in how things are managed and decided in different counties" (Akka), "[t]here are differences in doing archaeology in Dalarna and Scania, that's how it is" (Dunfin), or that "[c]ultural 
environment has certain regional characteristics that you have to take into account in managing it" (Gustav, see also Kajsa). Even if these differences were experienced to a certain extent problematic, the interview record shows also that they functioned as a key enabler of the flexibility and success of AHAs' work. They were simultaneously a cause and result of variation in the local archaeological landscape, land development, personal and organisational matters, staffing and resources, and, for instance, available skills and knowledge.

\subsubsection{Collaboration}

Finally, the consultative nature of the work of administrators means that stakeholder relations and collaborations are as central to the success of their work as experience, its resources and infrastructures, and boundaries and flexibility. Archaeological heritage administration is as a whole about finding compromises between different interests as Mårten explained. Establishing and maintaining long-term relations with different actors was considered helpful (Nils, Akka) but a lack of knowledgeable colleagues who are not involved in procurement processes as a real problem (Nils, Smirre). At the same time, for instance, Smirre underlined that establishing collaborations and bringing people with very different backgrounds together could be highly rewarding. The interviewees referred to a general tendency to work in silos and not thinking enough of what one's own work implies to others' work (Nils), and a lack of time to establish and cultivate collaborations, especially outside of the immediate circle of daily contacts (Gorgo, Dunfin, Akka, Kajsa) as key hinders to functioning collaborations.

\section{Discussion}

The understanding of AHAs' information work that emerges from the analysis corresponds well with brief remarks in the earlier literature. This applies both the critical success factors, problems and major barriers to information (e.g. Huvila, 2006, 2014; Larsson et al., 2017; Åsa M. Larsson \& Löwenborg, 2020; Löwenborg et al., 2021). Moreover, their information has many parallels to general patterns of information work at workplace described in the literature from the centrality people sources with complex tasks Byström (1999) and parallel use of internal and external information sources (Huvila \& Ahmad, 2018)to role of experience and informational metagaming (Huvila, 2013b). Similarly to many contractors, especially those affiliated with public organisations (Börjesson, 2015), also administrators rely to a large extent on administrative information sources. At the same time, the analysis draws a more nuanced picture of what it takes to be a successful administrator, why and how the information work of individual administrators differs from each other, and how the current organisation of archaeological heritage administration both enables and inhibits contemporary and future information and knowledge-making. When considering the findings and drawing conclusions, it is obviously necessary to consider the limitations of the present study. Most importantly, even if the recruitment of interviewees aimed at securing a reasonable variation of contexts and backgrounds, the interviewees do not make a representative sample of all Swedish archaeology administrators and their views are not generalisable to all archaeological heritage administrators in Sweden or especially to their colleagues abroad. However, considering the aims of this study to produce a qualitative description of AHAs' information work and its major constituents rather than a quantitative distribution of opinions, it is unlikely to lead to a major bias.

There is not much doubt that the current arrangements of archaeological heritage administration are reasonably effective. It is also highly apparent that the arrangements are as much devised by administrators and the architects of the development-led archaeological system (i.e. subjects) as they are constituted by the social, material and sociomaterial ramifications of that activity (cf. Hultin, 2019). Even if knowledge making is a key outcome of archaeological work (e.g. Gorgo, Rosenbom), it was fairly apparent that the contract archaeological process is only partially geared towards that specific goal. Contract archaeology, its repercussions to land development and the archaeological information and knowledge it generates are not only a matter of what is archaeologically relevant in a general sense but also to what is achievable in the thick of spatially and temporally local circumstances, including regional variation in typical archaeological sites, workload, available staff and their number, collaborators, information, competencies, methods and technologies, and their availability. Similarly to how archaeologists talking about archaeology (e.g. Smith, 2004; 
Enqvist, 2014), how archaeological fieldwork is organised (e.g. Dent, 2012; La Salle \& Hutchings, 2012; Demoule, 2012; Everill, 2012) and managed (e.g. Cooper et al., 1995), also the administration of development-led archaeology is a generative activity. Its critical success factors and the mundane ways how it is achieved shape its informational and non-informational outcomes. These arrangements show remarkable resilience to shortcomings reported in earlier literature (e.g. Huvila, 2016b, 2006) and this study, including local differences, relative lack of resources, routines, and experience, and, for instance, to an occasional lack of access to information - multiple factors that are simultaneously critical to their success. Despite its openness, on a fundamental level development-led archaeology unfolds as a closeto-autopoietic (Maturana \& Varela, 1980) system. In contrast to its outspoken aims, the primary question is not what 'it' is or how well it corresponds with the expectations of the outcomes of archaeology as a whole but how well it sustains.

Based on reading and rereading the unfolding of the interviewees' narratives of their work, it is apparent that the system of archaeological work and its informational subsystem (i.e. information work) operate somewhere between a Luhmannian (1982) isolation and openness. As a system, the administrators' work-as-whole is shaped by a plethora of parallel work and control regimes and their underpinning arrangements i.e. technical systems, actors, policies, needs and wants from scholarly archaeology to land development and local administration. Behind these largely practical factors, it is possible to recognise elements that make and keep the systems running. In the analysed material, particularly two, the regulation of contextual distance, and ambiguity and standardisation, appeared to have specific prominence.

First, the parallel critical reliance on the 'use' of colleagues and collaborators and positioning of their own administrative work in the nexus of multiple stakeholder interests provided the administrators with a way to control or regulate the contextual distance of the projects they were administering from their own sphere. It is not always easy, as the problems of balancing between being an expert and administrator, having and not having local, technical or methodological knowledge (cf. e.g. how Carver, 2009, discusses his position in relation to local archaeologists in East Anglia) or difficulties to find such colleagues to consult who are not involved in tenders, and the occasional lack of time, resources and information evince. But when successful, it provided means to draw and undraw fine lines around the arrangements of archaeological heritage administration. Referring to the conceptualisation of Huvila (2019b), the systems or contexts of administrative work unfolded not that much as bounded spaces but centred sets. It allowed the administrators to flexibly switch from being experts in a specific topic (i.e. operating within a self-referential system cf. Luhmann, 2005) to outsourcing trust (cf. Sundin \& Carlsson, 2016) and expertise to other actors (i.e. working across its boundaries) when working with other ones by balancing between the two critical success factors of experience and collaboration.

Second, the administrators could exercise and maintain control over their work and information work by managing the balance between ambiguity and standardisation of its limits and aims. Similarly to how the regulation of contextual distance unfolded as a balancing act between two critical success factors of their work to regulate the system and its self-referentiality, working with ambiguity and standardisation stands out as similar offsetting of uniformity and flexibility, available resources and infrastructures in relation to the context and situation of the work they were doing. The interviewees were mindfully ambivalent in their relation to the perimeters of the system (cf. Luhmann, 2005) and its control regime (cf. White, 2008) i.e. what should be standardised and what should be decided locally and simultaneously, what resources and infrastructures were indispensable or not in their information work and information. Similarly to earlier findings on experts working in other contexts (e.g. Ellingsen, 2004; Rhee et al., 2015) and experiences in contract archaeology (e.g. Carver, 2009), the administrators were less inclined to see the lack of standardisation as a key problem for their personal work. Even if in some cases they could see room for improvement in this respect, it was apparent that ambiguity was perceived often as a strategic resource (as in Barley et al., 2012; Eisenberg, 1984) that could be put to work and accommodated to (as in Huvila, 2018) when needed. This is in contrast to how the ambiguity of archaeological information and how it comes into being is often seen as a problem among those stakeholders of the process, including developers (Huvila, 2017), information managers (Huvila, 2016b) and researchers (Börjesson, 2016), who rely on the usefulness and perpetuity of the outcomes (e.g. reports, data) of that work rather than that of the work itself. For administrators, the complexity and situatedness of their work did not just happen in the background as a condition of the work, but the administrators used ambiguities and heterogeneity strategically (Derderian, 2019; Meintjes \& Lemon, 2017) to help them to manage their workload and cope with the general conditions of their work, like a small staff and the lack of available information (e.g. Nils, Mårten). Understanding anomalies and engaging in articulation work (Star, 1999) were central to the success of their work but instead of suffering from it, a lack of articulation could also 
be a resource. For Mårten, it was not his job to determine if the contractors really are documenting relevant aspects of sites and the investigation processes. It is enough that an administrator trusts that they do a good job and focuses on following up that contractors submit expected "material" (Bataki).

At the same time, however, it was apparent that a degree of homogeneity and standardisation was needed to make strategic ambiguity (term of Eisenberg, 1984) possible. It was essential to keeping the system closed in a self-referential Luhmannian sense but at the same time open for external influence and information (cf. Luhmann, 1982, 2005). The lack of synthesis and dispersion of data were experienced as problems when there was a risk that ambiguity would lose its reference point. As a result, the quasi-Luhmannian development-led archaeological system could become destabilised and administrators could lose control of their work, for instance, by not being able to maintain an overview of the on-going archaeological work in their region (Nils) or to express their views on the matter (Gorgo). Without having a reasonably stable idea of the current state-of-affairs as a point of reference for comparing different claims and interpretation, ambiguity could lead to a disorder and a loss of 'overview' (Polesie, 2013) of their work-as-whole i.e. a comprehensive mastery (in a similar sense than for Heinström et al., 2019) of how they perceived their own work and information work as a form of its sub-work (Huvila, 2009).

\section{Conclusions}

AHAs' work is to enforce heritage legislation, ensure the preservation and minimise any damage inflicted on archaeological heritage sites. Even if their principal work duties are the same across Sweden, the conditions and practical work individual administrators vary considerably from one region to another. The work is informationintensive and geared towards the preservation of - and secondarily, information and knowledge production on archaeological heritage for administrative use, public dissemination and future research. Much of its emphasis lies, however, in managing daily routines and administrative processes, following and enforcing rules and regulations, and collaborating with immediate stakeholders rather than envisioning or working towards specific means to utilise its outcomes in the future. Administrators themselves acquire most of the information they need from administrative sources and by consulting colleagues.

The major factors that affect the success of the administrators work relate to the adequacy and availability of resources, importance of personal experience and functioning collaborations with key stakeholders and colleagues, and a possibility to maintain a working balance between following and unfollowing (i.e. interpreting and reinterpreting) formal guidelines, boundaries and standards of what archaeological administrative work is supposed to be. These main building blocks of their work were interlinked to each other in a manner, which helped to compensate for shortages or problems in one with resources drawn from another. On a fundamental level, the administrators' ability to regulate their personal contextual distance to the projects they were working on helped them to maintain control over their workas-whole. In the process, their information work - selection of specific information sources, information relevance and quality assessments and readings of archaeological documentation - functioned as central means to this end. It enabled them to switch between acting as subject experts and relying on others. Another parallel factor that contributed to the same end of regulating the work-as-whole, was their ability to strategically balance between standards and ambiguity. Together, the two factors were in a key position in keeping administrators' work and information work workable and the administration of archaeological heritage possible within its current boundary conditions.

Acknowledgements: This work was supported by the Swedish Research Council under Grant 340-2012-5751 for the research project Archaeological Information in the Digital Society (ARKDIS). Finalising this work has also received funding from the European Research Council (ERC) under the European Union's Horizon 2020 research and innovation programme grant agreement No 818210 as a part of the project CApturing Paradata for documenTing data creation and Use for the REsearch of the future (CAPTURE) and from the Swedish Research Council under the Grant 340-2012-5751. The work has also benefited of the discussions at different events organised by the COST Action ARKWORK, supported by COST (European Cooperation in Science and Technology). 


\section{References}

Åsa M. Larsson, \& Löwenborg, D. (2020). The digital future of the past - research potential with increasingly FAIR archaeological data. In C. Hillerdal, \& K. Ilves (Eds.) Re-imagining periphery: Archaeology and text in Northern Europe from iron age to viking and early modern periods, (pp. 61-70). Oxford: Oxbow.

Andersson, C., Lagerlöf, A., \& Skyllberg, E. (2010). Assessing and measuring: On quality in development-led archaeology (with comments and reply),. Current Swedish archaeology, 18, 11-28.

Barley, W. C., Leonardi, P. M., \& Bailey, D. E. (2012). Engineering objects for collaboration: Strategies of ambiguity and clarity at knowledge boundaries. Human Communication Research, 38(3), 280-308.

Berggren, A., \& Hodder, I. (2003). Social Practice, Method, and Some Problems of Field Archaeology. American Antiquity, 68(3), $421-434$. http://www.jstor.org/stable/3557102

Bernstein, B. B. (2000). Pedagogy, symbolic control, and identity : theory, research, critique. Lanham, MD: Rowman \& Littlefield.

Bonner, A., \& Lloyd, A. (2011). What information counts at the moment of practice? information practices of renal nurses. Journal of Advanced Nursing, 67(6), 1213-1221.

Börjesson, L. (2015). Grey literature - grey sources? nuancing the view on professional documentation: The case of Swedish archaeology. Journal of Documentation, 71(6), 1158-1182.

Börjesson, L. (2016). Beyond information policy: conflicting documentation ideals in extra-academic knowledge making practices. Journal of Documentation, 72(4), 674-695.

Börjesson, L. (2016). Research outside academia? an analysis of resources in extra-academic report writing. Proceedings of the 2016 ASIS\&T Annual Meeting, Copenhagen, (pp. 1-10).

Börjesson, L., \& Huvila, I. (2019). Contract archaeology. In L. Börjesson, \& I. Huvila (Eds.) Research Outside the Academy: Professional Knowledge-Making in the Digital Age, (pp. 107-122). Basingstoke: Palgrave Macmillan.

Börjesson, L., Petersson, B., \& Huvila, I. (2015). Information policy for (digital) information in archaeology: current state and suggestions for development. Internet Archaeology, 40.

Bouwman, M. J., Frishkoff, P. A., \& Frishkoff, P. (1987). How do financial analysts make decisions? A process model of the investment screening decision. Accounting, Organizations and Society, 12(1), 1-29.

Brown, J. S., \& Duguid, P. (2000). The Social Life of Information. Boston: Harvard Business School Press.

Buchanan, S. A. (2016). A Provenance Research Study of Archaeological Curation. Ph.D. thesis, The University of Texas at Austin, Austin.

Byström, K. (1999). Task Complexity, Information Types and Information Sources. Ph.D. thesis, University of Tampere, Information Studies, Tampere.

Byström, K., Heinström, J., \& Ruthven, I. (2018). Workplace information environment - challenges and opportunities for research. In K. Byström, J. Heinström, \& I. Ruthven (Eds.) Information at Work: Information management in the workplace, (pp. 147-172). London: Facet.

Carver, M. O. H. (2009). Archaeological investigation. London; New York: Routledge.

Cool, C. (2001). The Concept of Situation in Information Science. Annual Review of Information Science and Technology, 35, 5-42.

Cooper, M. A., Firth, A., Carman, J., \& Wheatley, D. (Eds.) (1995). Managing archaeology. London; New York: Routledge.

De Clercq, W., Bats, M., Bourgeois, J., Crombé, P., De Mulder, G., De Reu, J., Herremans, D., Laloo, P., Lombaert, L., Plets, G., et al. (2012). Development-led archaeology in Flanders: an overview of practices and results in the period 1990-2010. Development-led archaeology in North-west Europe: proceedings of a round table at the University of Leicester 19th-21st november 2009, (pp. 29-55).

Demoule, J.-P. (2002). Rescue archaeology: The French way. Public Archaeology, 2(3), 170-177.

Demoule, J.-P. (2012). Rescue Archaeology: A European View. Annual Review of Anthropology, 41, 611-626.

Dent, J. (2012). Past tents: temporal themes and patterns of provincial archaeological goverance in British Columbia and Ontario. Master's thesis, The University of Western Ontario, London, ON.

Dent, J. (2017). Tailors-made: Heritage governance customization in late modern Canada. Archaeologies.

Derderian, B. (2019). On the value and versatility of strategic ambiguity. Fieldsights. https://culanth.org/fieldsights/on-the-value-and-versatility-of-strategic-ambiguity

DuBois, A. (2003). Close reading: an introduction. In F. Lentricchia, \& A. DuBois (Eds.) Close reading: a reader, (pp. 1-40). Durham, NC: Duke University Press.

Eisenberg, E. M. (1984). Ambiguity as strategy in organizational communication. Communication Monographs, 51(3), $227-242$.

Ekbia, H. (2009). Information in action: A situated view. Proc. Am. Soc. Info. Sci. Tech., 46(1), 1-11.

Ellingsen, G. (2004). Tightrope walking: Standardisation meets local work-practice in a hospital. International Journal of IT Standards \& Standardization Research, 2(1), 1-22.

Ellingsen, G., Monteiro, E., \& Munkvold, G. (2007). Standardization of work: Co-constructed practice. The Information Society, 23(5), 309-326.

Enqvist, J. (2014). The New Heritage: A Missing Link between Finnish Archaeology and Contemporary Society? Fennoscandia Archaeologica, XXXI, 101-123.

Everill, P. (2012). The Invisible Diggers : A Study of British Commercial Archaeology. Oxford: Oxbow Books, 2 ed.

Friberg, Z., \& Huvila, I. (2019). Using object biographies to understand the curation crisis: lessons learned from the museum life of an archaeological collection. Museum Management and Curatorship, 34(4), 362-382. 
Gerdes, A. (2008). The clash between standardisation and engagement. Journal of Information, Communication and Ethics in Society, 6(1), 46-59.

Gießmann, S., \& Taha, N. (2017). “study the unstudied”: Zur medienwissenschaftlichen Aktualität von Susan Leigh Stars Denken. In S. Gießmann, \& N. Taha (Eds.) Grenzobjekte und Medienforschung, (pp. 13-77). Bielefeld: Transcript.

Glaser, B. G., \& Strauss, A. L. (1967). The discovery of grounded theory: Strategies for qualitative research. Chicago: Aldine.

Green, W., \& Doershuk, J. F. (1998). Cultural resource management and american archaeology. Journal of Archaeological Research, 6(2), 121-167.

Haggrén, G. (2014). Haloo muinaisjäännösrekisteri: kylät mukaan! [hello sites and monuments record: include village sites!]. SKAS, (1), 2.

Haraway, D. (1988). Situated knowledges: the science question in feminism and the privilege of partial perspective. Feminist Studies, 14(3), 575-599.

Hardin, R. (2009). How do you know? : the economics of ordinary knowledges. Princeton: Princeton University Press.

Heinström, J., Sormunen, E., Savolainen, R., \& Ek, S. (2019). Developing an empirical measure of everyday information mastering. JASIST, 71(7), 729-741.

Hirsjärvi, S., \& Hurme, H. (2008). Tutkimushaastattelu: Teemahaastattelun teoria ja käytäntö. Helsinki: Gaudeamus.

Hultin, L. (2019). On becoming a sociomaterial researcher: Exploring epistemological practices grounded in a relational, performative ontology. Information and Organization, 29(2), 91-104.

Huvila, I. (2006). The ecology of information work - A case study of bridging archaeological work and virtual reality based knowledge organisation. Åbo: Åbo Akademi University Press. Diss. Åbo Akademi University. http://urn.fi/URN:ISBN:951-765-337-9

Huvila, I. (2009). Ecological framework of information interactions and information infrastructures . Journal of Information Science, 35(6), 695-708.

Huvila, I. (2011). The politics of boundary objects: hegemonic interventions and the making of a document. JASIST, 62(12), $2528-2539$.

Huvila, I. (2013a). How a Museum Knows? Structures, Work Roles, and Infrastructures of Information Work. JASIST, 64(7), $1375-1387$.

Huvila, I. (2013b). Meta-games in information work. Information Research, 18(3), paperC01. http://www.informationr.net/ir/18-3/colis/paperC01.html

Huvila, I. (2014). Archaeologists and their information sources. In I. Huvila (Ed.) Perspectives to Archaeological Information in the Digital Society, (pp. 25-54). Uppsala: Department of ALM, Uppsala University.

Huvila, I. (2016a). Awkwardness of becoming a boundary object: Mangle and materialities of reports, documentation data and the archaeological work. The Information Society, 32(4), 280-297.

Huvila, I. (2016b). 'If we just knew who should do it', or the social organization of the archiving of archaeology in Sweden. Information Research, 21(2), Paper 713. http://www.informationr.net/ir/21-2/paper713.html

Huvila, I. (2017). Land developers and archaeological information. Open Information Science, 1(1), 71-90.

Huvila, I. (2018). Putting to (information) work: A Stengersian perspective on how information technologies and people influence information practices. The Information Society, 34(4), 229-243.

Huvila, I. (2019a). Learning to work between information infrastructures. Information Research, 24(2), paper 819. http://www.informationr.net/ir/24-2/paper819.html

Huvila, I. (2019b). Rethinking context in information research: bounded versus centred sets. Information Research, 24(4), paper colis1912. http://www.informationr.net/ir/24-4/colis/colis1912.html

Huvila, I., \& Ahmad, F. (2018). Holistic information behavior and the perceived success of work in organizations. Library \& Information Science Research, 40(1), 18-29.

Huvila, I., \& Börjesson, L. (2019). Epilogue. In L. Börjesson, \& I. Huvila (Eds.) Research Outside The Academy: Professional KnowledgeMaking in the Digital Age, (pp. 171-182). Basingstoke: Palgrave MacMillan.

Kallinikos, J. (2006). The consequences of information : institutional implications of technological change. Cheltenham: Edward Elgar.

Kallinikos, J., \& Hasselbladh, H. (2009). Work, control and computation: Rethinking the legacy of neo-institutionalism. In R. E. Meyer, K. Sahlin, M. J. Ventresca, \& P. Walgenbach (Eds.) Institutions and Ideology, (pp. 257-282). Bingley: Emerald.

Kaplan, B. (1995). Fitting system design to work practice:using observation in evaluating a clinical imaging system. In AMCIS Proceedings, (p. 90). https://aisel.aisnet.org/amcis1995/90

Khazraee, E. (2013). Information Recording in Archaeological Practice: A Socio-Technical Perspective. In iConference 2013, February 12-15, 2013 Fort Worth, TX.

Khazraee, E., \& Gasson, S. (2015). Epistemic objects and embeddedness: Knowledge construction and narratives in research networks of practice. The Information Society, 31(2), 139-159.

Klijn, E.-H., \& Koppenjan, J. (2012). Governance network theory: past, present and future. Policy \& Politics, 40(4), 587-606.

La Salle, M., \& Hutchings, R. (2012). Commercial archaeology in British Columbia. The Midden, 44(2), 8-16.

Larsson, Å. M., , Smith, M., Sohlenius, R., \& Klafver, T. (2017). Digitising the archaeological process at the Swedish National Heritage Board: producing, managing and sharing archaeological information. Internet Archaeology, (43).

Lincoln, Y. S., \& Guba, E. G. (1985). Naturalistic Inquiry. Beverly Hills: Sage.

Lönn, M. (2006). Uppdragsarkeologi och forskning. Göteborg: Göteborgs universitet. 
Löwenborg, D., Jonsson, M., Larsson, Å., \& Nordinge, J. (2021). A turn towards the digital. an overview of swedish heritage information management today. Internet Archaeology, 58.

Luhmann, N. (1982). The world society as a social system. International Journal of General Systems, 8(3), 131-138.

Luhmann, N. (2005). Social systems. Stanford, CA: Stanford University Press.

Luoto, K. (2015). Vastine Muinaistutkijan (3/2015) pääkirjoitukseen "Firmat, kilpailu ja arkeologia" [reply to the editorial of muinaistutkija (3/2015) "Firms, competition and archaeology"]. Muinaistutkija, (4), 54-55.

Maturana, H. R., \& Varela, F. J. (1980). Autopoiesis and cognition : the realization of the living. Dordrecht: Reidel.

Meintjes, L., \& Lemon, T. J. (2017). Dust of the Zulu: Ngoma aesthetics after Apartheid.

Miwa, M. (2003). Situatedness in users' evaluation of information and information services. The New Review of Information Behaviour Research, 4, $207-224$.

Olsson, M. (2016). Making sense of the past: The embodied information practices of field archaeologists. Journal of Information Science, 42(3), 410-419.

Polesie, P. (2013). The view of freedom and standardisation among managers in swedish construction contractor projects. International Journal of Project Management, 31(2), 299-306.

RAÄ (2015). Uppdragsarkeologi: Det uppdragsarkeologiska systemet. Stockholm.

Rhee, M., Park, J. S., \& Yoo, T. (2015). The contradictory roles of ambiguity for innovation in an industry: how beneficial are standardisation and classification? Technology Analysis \& Strategic Management, 27(9), 1114-1128.

Rocabado, P. (2015). Neoliberal multiculturalism and contract archeology in northern Chile. International Journal of Historical Archaeology, 19(4), 775-790-.

Schibbye, K., Frisk, M., Sander, B., \& Westerlind, A. (2007). Kulturmiljön som resurs: Hur kulturmiljöaspekterna på ett ändamålsenligt sätt kan behandlas i miljöbedömningar och miljökonsekvensbeskrivningar. Tech. rep., RAÄ, Stockholm.

Sciulli, D. (2005). Continental sociology of professions today: Conceptual contributions. Current Sociology, 53(6), 915-942.

Sharrock, W., \& Button, G. (2011). Engineering investigations: What is made visible in making work visible? In M. H. Szymanski, \& J. Whalen (Eds.) Making Work Visible: Ethnographically Grounded Case Studies of Work Practice, (pp. 34-50). Cambridge: Cambridge University Press.

Smith, L. (2004). Archaeological theory and the politics of cultural heritage. London and NewYork: Routledge.

Söderström, U. (2018). Contract Archaeology and Sustainable Development: Between Policy and Practice. phdthesis, Linnaeus University, Kalmar.

Star, S. L. (1988). The structure of ill-structured solutions: Heterogeneous problem-solving, boundary objects and distributed artificial intelligence. In Proceedings of the 8th AAAI Workshop on Distributed Artificial Intelligence, Technical Report, Department of Computer Science, University of Southern California. Los Angeles, CA.

Star, S. L. (1999). The Ethnography of Infrastructure. American Behavioral Scientist, 43(3), 377-391. http://abs.sagepub.com/cgi/content/abstract/43/3/377

Stefánsdóttir, A. (2019). An introduction to development-led archaeology in europe: Meeting the needs of archaeologists, developers and the public. Internet Archaeology, 51.

Stjernberg, F. (2010). Comments on assessing and measuring: On quality in development-led archaeology. Current Swedish Archaeology, 18(1), 47-51.

Stoker, G. (1998). Governance as theory: five propositions. International Social Science Journal, 50(155), 17-28.

Stone-Johnson, C. (2014). Parallel professionalism in an era of standardisation. Teachers and Teaching, 20(1), 74-91.

Suchman, L. (1987). Plans and Situated Actions. Cambridge: Cambridge University Press.

Sundin, O., \& Carlsson, H. (2016). Outsourcing trust to the information infrastructure in schools: How search engines order knowledge in education practices. Journal of Documentation, 72(6), 990-1007.

Thomas, J. (2006). The Great Dark Book: Archaeology, Experience, and Interpretation. In J. Bintliff (Ed.) A Companion to Archaeology, (pp. 21-36). Malden and Oxford: Blackwell Publishing.

Timmermans, S., \& Berg, M. (1997). Standardization in action: achieving local universality through medical protocols. Social Studies of Science, 27, 273-305.

Urban, R. J. (2014). Library Influence on Museum Information Work. Library Trends, 62(3), 596-612.

Ward, V., House, A., \& Hamer, S. (2009). Knowledge brokering: the missing link in the evidence to action chain? Evidence \& Policy, 5(3), 267-279.

Watson, S. (2021). Foreword. archaeology and public benefit. Internet Archaeology.

Wears, R. L. (2015). Standardisation and its discontents. Cognition, Technology \& Work, 17(1), 89-94. http://dx.doi.org/10.1007/s10111-014-0299-6

White, H. C. (2008). Identity and control : how social formations emerge. Princeton: Princeton University Press.

Winch, C. (2010). Dimensions of expertise: a conceptual exploration of vocational knowledge. London: Bloomsbury.

Young, M. F. D., \& Muller, J. (2014). From the sociology of professions to the sociology of professional knowledge. In M. F. D. Young, \& J. Muller (Eds.) Knowledge, expertise and the professions, (pp. 3-17). London: Routledge.

Zorzin, N. (2010). The political economy of a commercial archaeology : a Quebec case-study. Ph.D. thesis, University of Southampton, Southampton.

http://eprints.soton.ac.uk/344777/ 